\title{
Determination of the Effects of the Pre-Outfitting and Pre-Piping Assembly Operations on Shipyard Productivity
}

\author{
Murat Ozkok, Assist. Prof. \\ Karadeniz Technical University, Turkey \\ I. Hakki Helvacioglu, Assoc. Prof. \\ Istanbul Technical University, Turkey
}

\begin{abstract}
The process improvement operations are very significant in shipbuilding industry as the other industries. In recent years, the shipyards attempt to improve their processes by examining their current production system and to reduce the cycle time of the interim product so that they can keep their competitive power. If the cycle time of the interim products is decrease, that may cause to increase the annual production capacity and market share of the shipyard. In order to do this, the shipyards have to analyse their own production system and carry out some improvements on it. In this study, the effects of carrying out the outfitting and piping assembly operations in earlier work stations were investigated by using a methodology presented here. The steps in the methodology were applied to a double bottom block of a container ship. It was shown that if the outfitting and the piping assembly operations are carried out in earlier stations instead of the block assembly station, this may increase the throughput by 33\%. The results of the study were discussed in the final section.
\end{abstract}

Key words: Pre-outfitting assembly; pre-piping assembly; simulation; ship production

\section{INTRODUCTION}

Shipbuilding is a global industry competing in the world extent [1]. In recent years, the shipyards attempt to improve their production processes in order to yield advantages against their competitors by manufacturing the ship as soon as possible. Geoje Samsung Shipyard is able to manufacture 40 ships per year in South Korea and it is also known as one of the most efficient shipyards in the world [2]. As compared with the other shipyards, Samsung shipyard has a great competitive advantage against its competitors. So, the point is that the shipyards have to investigate their production system and do some improvements in order to keep the competitive power.

One of the latest trend in manufacturing process is to reduce the cycle time of the product. In order to reduce the cycle time, it is needed to make process improvements on the current production system. Eker [3] reported some improvement suggestions with regard to the processes in the painting shops of the Sedef Shipyard and Schalekamp Shipyard. In the study [4], the format of the design drawings coming from design department was changed and the cutting process was carried out in shorter time and in more effective way. The process improvement operations was also applied on the scaffold area and material stock area [5] and the layout of the work stations [6] and [7]. In Todd Pacific Shipyard, as a result of improvement process, the moving distances of the forklifts were shortened in the rate of $50 \%$ and the oil wastes occurring during the operations of the forklifts were also reduced [8]. As can be seen from the above works, the process improvement applications are able to be applied in many fields in shipyard.

The effects of the improvements on the production system can be seen by simulation. Simulation has a great importance for the production companies. In the competition environment, the changes on the production system and the effects of these changes are very significant in terms of the company performance. Simulation has been applied in many industry for years as it provides a great advantage for the planner. In shipbuilding industry, it has a great deal of application fields such as layout, production processes and so on. In the study that has been still going on by Michigan University and Seoul University, it is aimed to simulate all the activities in shipyard and to see the effects of the changes on the production system [9]. In the other study, the stations forming the sub assembly line were modelled by using simulation and after the system was simulated, a robot was settled in the production line and the rate of productivity was determined [10]. Shin [11] aimed to settle the work stations of the shipyard in the optimum way. That's a layout application of simulation. Alkaner [12] considered a profile cutting station and the processes of the profile cutting station were determined. Then, these processes were modelled in a simulation program and the effects of changing the resources were investigated. In the study [13], the panel production station was considered as a bottleneck station. Processes were determined and modelled in simulation program. Then, by doing some changes on the processes, the completion time of the panel cutting station was tried to be 
optimized. In this study, Arena simulation program [14] was used for modelling the work flows between stations as the modules of it are very appropriate for modelling the production activities. The activities can also be modelled easily by using the modules.

In many shipyards in Turkey, the whole assembly operations with regard to outfitting and piping are carried out in the block assembly area. In the block assembly area, after the steel assembly operations of the block are over, the outfitting and piping assembly operations are carried out. Therefore, the work load of the block assembly area is very high and this may cause to a new bottleneck in the production system. In this study, the outfitting and piping assembly operations of the block will be carried out in earlier work stations and some changes will be applied on the current production line. As a result, the effects of all these changes on the current production system will be determined. The phases of the methodology are followed one by one and the effects of the pre-outfitting and pre-piping activities on the entire production system are seen.

In literature, the papers with regard to pre-outfitting are very limited. In the papers, the modular outfitting concept is mentioned. Fafandjel [15] mentioned that the ship is manufactured in shorter time by using modular outfitting concept. Yu and Ishida [16] searched how to determine the effectiveness of the modular outfitting concept. Baade et al. [17] mentioned the advantages of the modular outfitting in his paper.

\section{METHODOLOGY}

Fig. 1 presented the methodology implemented in this study. The methodology consists of nine steps. In the first step of the model, the product, which is produced in shipyard production line, is defined. Then, the workstations, that are involved in product fabrication, are described. In the step 3 , detailed process analysis of current production system is performed. After comprehensive process analysis, simulation model of the current production system is modelled in ARENA simulation software (in step 4). In step 5, simulation model is run along a specific period and production quantity (throughput) of the production system is achieved. Then, some suggestions on current production system are made in step 6 . After that, these suggestions are applied on current simulation model in step 7 and the new production case is obtained. In step 8 , the effects of the changes are discussed and evaluated. Finally, in the last step (step 9), comparison of the current and new production cases is performed.

\section{APPLICATION}

\section{Defining of product (Step 1)}

Ships are fabricated in blocks which constitute ship structure. There are various sort of blocks such as bow, aft, side, bulkhead and double bottom block. In this study, a double bottom block of a container ship is illustrated as an example. Double bottom block is one of the main interim products in shipbuilding. The reason of considering the double bottom block in this study is that almost all of the work stations are involved in its production activities.

As the structure of a double bottom block is examined, it can be seen that it has different production phases, which are called as production stages. Table 1 shows these production stages and the structures representing these production stages.

A double bottom block is built by coming together the production stages mentioned in Tab. 1. In the first phase of the

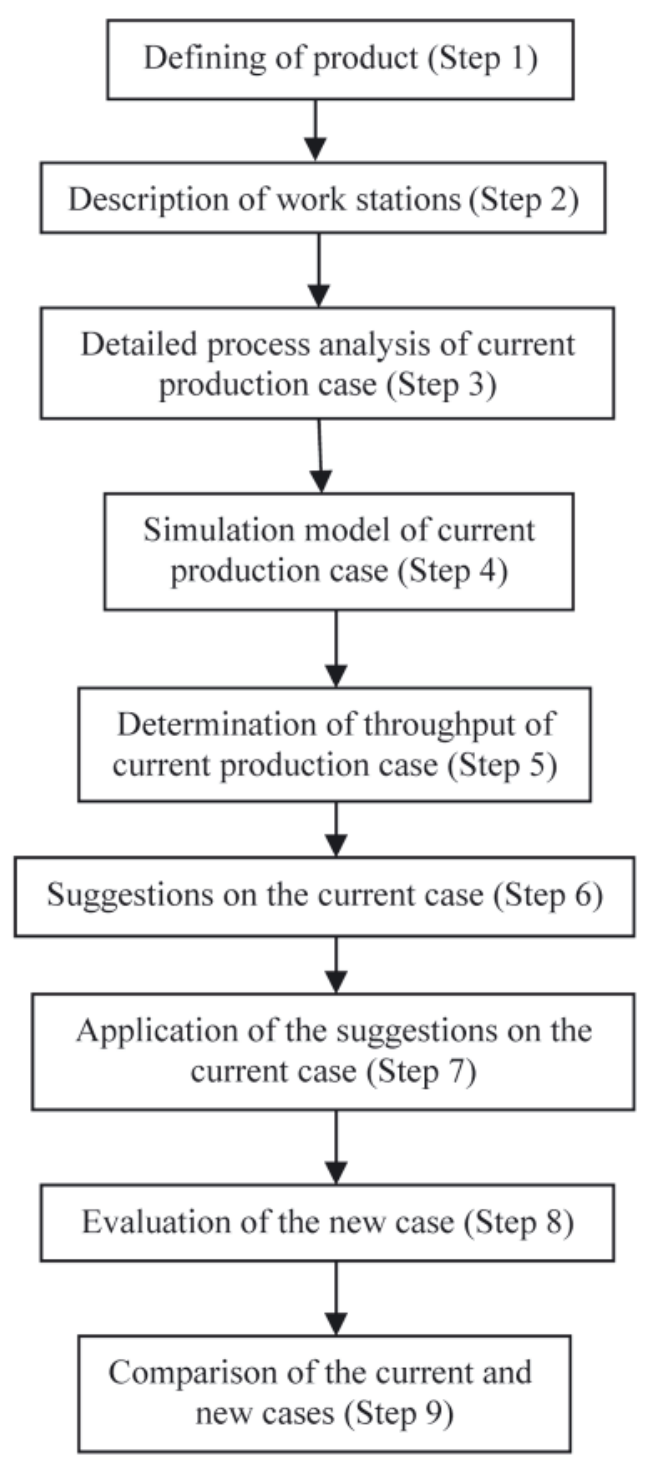

Fig. 1. Application steps of the study

double bottom production, single section parts (A) and single plate parts (B) are fabricated. These parts are cut from the plates and profiles which have standard-dimensions and they have specific dimensions after cutting process. Then, they are fitted and minor assembly is built (C). Two or more minor assemblies constitute sub assembly (D). Flat plates are sub-merged welded and flat plate assembly (E) is fabricated. When the profiles are fillet welded on flat plate assembly, the flat plane assembly (F) is built. Minor and sub assemblies are welded on the flat plane assembly (F) and major sub assembly $(\mathrm{G})$ is manufactured. Curved panel assembly $(\mathrm{H})$ is manufactured on pin jigs. In block assembly area, sub unit assembly $(\mathrm{J})$ and curved panel assembly are mounted and welded, finally a double bottom block $(\mathrm{K})$ is built.

There are also some outfitting equipments in double bottom block just like manholes, bottom plugs, zinc, vertical ladder and doubling plates. These outfitting equipments are mounted into block structure's body. Tab. 2 shows these outfitting materials

\section{Descriptions of work stations (Step 2)}

Ship production is extremely hard job since it includes a great deal of process. A ship is manufactured by performing thousands of work activities. In order to manufacture a ship, various types of workstations are needed. Every workstation 
Tab. 1. Production stages of a double bottom block and structures

\begin{tabular}{|c|c|c|}
\hline $\begin{array}{c}\text { Production } \\
\text { Stage }\end{array}$ & $\begin{array}{c}\text { Definitions of production } \\
\text { stages }\end{array}$ & Structures representing production stage \\
\hline $\mathrm{A}$ & Single section part & \\
\hline $\mathrm{B}$ & Single plate part & \\
\hline $\mathrm{C}$ & Minor assembly & \\
\hline $\mathrm{D}$ & Sub assembly & \\
\hline $\mathrm{E}$ & Flat plate assembly & \\
\hline $\mathrm{F}$ & Surved panel assembly & \\
\hline $\mathrm{F}$ & &
\end{tabular}

has a task for ship production. Tab. 3 shows the work stations which have function in double bottom block production.

In edge cutting station (I1), the edge cutting operation of ship hull plates is carried out. Edge cutting operation is the contour cutting of flat plates. And the plates which are subject to edge cutting constitute the panel structure. The edge cleaning operation of the ship hull plates, which are cut in edge cutting station (I1), is carried out in edge cleaning and sequencing station (I2). There are some materials and slags on the edge surfaces of the plates after edge cutting. Using a grinding machine, these materials and slags remove from the edge surfaces of the plates. In I 2 station, the plates are also sequenced in accordance with the process turn. The hull plates are welded and the panel structure is produced in panel production station (I3). In panel cutting station (I4), the panel which is manufactured in panel production station (I3) is subject to 
Tab. 2. Outfitting materials used in double bottom block

\begin{tabular}{|l|l|}
\hline Outfitting name \\
\hline Banhole \\
Vertical ladder
\end{tabular}

Tab. 3. The work stations in the production process of the double bottom block

\begin{tabular}{|c|c|}
\hline Station no & Station name \\
\hline I1 & Edge cutting \\
\hline I2 & Edge cleaning and sequencing \\
\hline I3 & Panel production \\
\hline I4 & Panel cutting \\
\hline I5 & Profile spot welding \\
\hline I6 & Profile TIG welding \\
\hline I7 & Section spot welding \\
\hline I8 & Section TIG welding \\
\hline I9 & Grinding \\
\hline I10 & Profile cutting \\
\hline I11 & Profile bending \\
\hline I12 & Nest cutting \\
\hline I13 & Pre-fabrication \\
\hline I14 & Jig \\
\hline I15 & Plate bending (Press) \\
\hline I16 & Block assembly \\
\hline
\end{tabular}

counter cutting in accordance with its dimensions. The profiles are assembled on the panel by spot welding in profile spot welding station (I5). The profiles are welded by TIG welding in profile TIG welding station (I6). The minor and sub assemblies are joined on the flat panel assembly by spot welding in section spot welding station (I7). The minor and sub assemblies are welded on the flat panel assembly by TIG welding in section TIG welding station (I8). Grinding station (I9) is the last station of the panel line. In this station, the grinding operations of the flat panel and major sub assemblies are performed. The cutting operations of the profiles are performed in profile cutting station (I10). Standard-dimensioned profiles, which are sent to profile cutting station, are cut with specific dimensioned profiles. The bending operations of the profiles are performed by box machine in profile bending station (I11). The bending profiles are used in curved panel. Nest cutting station (I12) is the heart of the shipyard production system. In this station, single plate assemblies are manufactured. Minor and sub assemblies are produced in pre-fabrication station (I13). Curved panel assemblies are produced in jig station (I14). Jig structure consists of curved jigs. The curved panels are lied down the jig structure and the curved profiles are welded on this curved plates. In plate bending station (I15), the bending operations of the plates, coming from nest cutting station, are performed. Therefore, the flat plates are transformed to the curved plates. The structures and parts produced in previous work stations are sent to block assembly station (I16) and the block structure is formed by assembling the corresponding parts. Fig.2 shows the work flows between work stations.

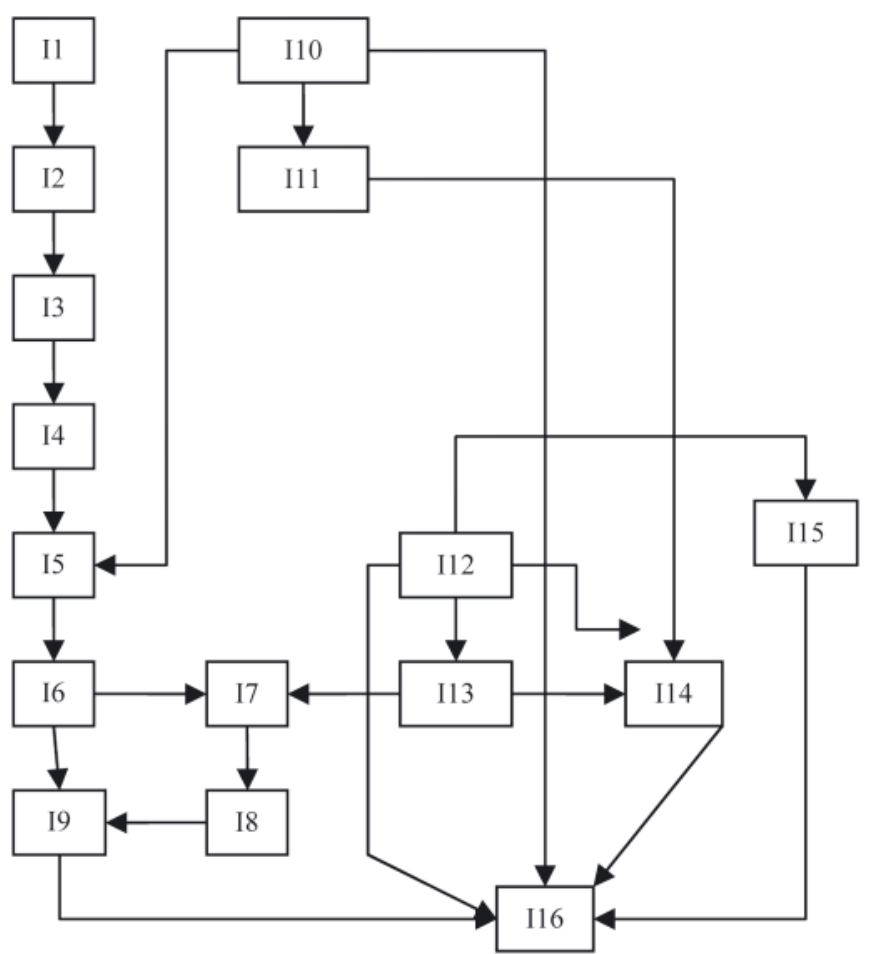

Fig. 2. Work flow in the shipyard production system

\section{Detailed process analysis of current production case (Step 3)}

In this step, the comprehensive process analysis of the work stations are carried out. Every work station has a considerable number of work activities. At the beginning of the detailed process analysis, the work activities are determined and then the durations of each work activity are achieved. Because there are over 2500 work activities, the process analysis of only panel production and panel cutting stations are presented here.

\section{Process analysis of panel production station (I3)}

In panel production station, panel structure is fabricated by submerged arc welding. Fig. 3 shows the general arrangement of the panel production station. In the first step, the plates are fixed to panel line by using conveyor fixing mechanism. Then, they are sent to tolerance plate's welding area where the tolerance plates are welded with tack welding. Submerged arc welding operation starts from the tolerance plates because the welding becomes more stabilized. After that, the plates are transferred to submerged arc welding machine with conveyor. 
Tab. 4. Detailed process analysis of panel production station (I3)

\begin{tabular}{|c|c|c|c|}
\hline $\begin{array}{l}\text { Activity } \\
\text { no. }\end{array}$ & Activity description & $\begin{array}{l}\text { Repetition } \\
\text { number of } \\
\text { activity }\end{array}$ & $\begin{array}{c}\text { Activity } \\
\text { duration } \\
\text { (min.) }\end{array}$ \\
\hline 1 & The overhead crane goes to the flat plate to be transported & 11 & 4.125 \\
\hline 2 & The overhead crane comes down to the flat plate surface & 12 & 5.746 \\
\hline 3 & The overhead crane holds the flat plate & 12 & 1.997 \\
\hline 4 & The overhead crane lifts the flat plate & 12 & 5.746 \\
\hline 5 & The overhead crane transports the flat plate & 12 & 4.5 \\
\hline 6 & The overhead crane takes down the flat plate & 12 & 5.4 \\
\hline 7 & The overhead crane leaves the flat plate surface & 12 & 0.996 \\
\hline 8 & The overhead crane goes up the flat plate surface & 12 & 5.4 \\
\hline 9 & The operator walks to the start point of the conveyor line & 11 & 2.2 \\
\hline 10 & The worker walks to the conveyor line plate fixed mechanism. & 12 & 0.864 \\
\hline 11 & The operator fixes the plate on the conveyor line & 12 & 3.996 \\
\hline 12 & The worker runs the conveyor line & 46 & 3.818 \\
\hline 13 & The operator walks to the welding tolerance plates & 20 & 1.1 \\
\hline 14 & The conveyor transports the plate to the tolerance plate welding area & 12 & 1.042 \\
\hline 15 & The alignment of the plate on the tolerance plate welding area & 8 & 1.307 \\
\hline 16 & The operator brings the tolerance plates to the flat plate & 20 & 1.1 \\
\hline 17 & The operator puts the tolerance plates near the corners of the flat plates & 40 & 5.32 \\
\hline 18 & The worker walks to spot welding machine & 2 & 0.086 \\
\hline 19 & The worker runs the spot welding machine & 2 & 0.166 \\
\hline 20 & The operator sets up the spot welding machine & 50 & 8.32 \\
\hline 21 & $\begin{array}{l}\text { The operator fixes the tolerance plates on the corners of the flat plates with } \\
\text { spot welding }\end{array}$ & 40 & 38 \\
\hline 22 & The operator walks to the other corner of the flat plate & 20 & 3.46 \\
\hline 23 & The operator goes to the TIG welding machine & 22 & 2.066 \\
\hline 24 & The conveyor transports the flat plate to the TIG welding area & 12 & 1.414 \\
\hline 25 & $\begin{array}{l}\text { The worker walks to the TIG welding machine in order to check the position } \\
\text { of the flat plate }\end{array}$ & 12 & 1.536 \\
\hline 26 & The worker checks out the position of the flat plate & 12 & 18 \\
\hline 27 & The operator runs the TIG welding machine & 12 & 16.992 \\
\hline 28 & The flat plate is fixed to the TIG welding machine with clamps & 12 & 9 \\
\hline 29 & $\begin{array}{l}\text { The worker checks out whether the plate is fixed on the TIG welding } \\
\text { machine conveniently or not. }\end{array}$ & 12 & 60 \\
\hline 30 & The worker brings the spot welding machine near the TIG welding machine & 10 & 0.72 \\
\hline 31 & The operator comes down to the plates for spot welding & 10 & 0.53 \\
\hline 32 & The spot welding operation of the plates prior to TIG welding & 10 & 115.358 \\
\hline 33 & The worker goes to the torches of the TIG welding machine & 10 & 0.32 \\
\hline 34 & The operator sets up the TIG welding machine before TIG welding process. & 10 & 41.664 \\
\hline 35 & TIG welding of the plates & 10 & 272.19 \\
\hline 36 & The conveyor transports the panel outside the TIG welding station. & 10 & 1.728 \\
\hline
\end{tabular}

Here, the plates are welded with submerged arc welding and they are then sent to buffer area. As a result, flat plate assembly (production stage E) is fabricated. Table 4 illustrates the detailed process analysis in panel production station.

\section{Process analysis of panel cutting station (I4)}

Counter cutting of the panel is performed in this station. Fig. 4 shows general arrangement of panel cutting station. The panel fabricated in I3 gets to Buffer Area 2. Then, the panel is transferred to panel cutting machine with conveyor. Panel cutting machine performs counter cutting operation. But, before this, blasting operation is fulfilled. Then, automatic marking operation is done. Therefore, the alignments of the piece parts can be easily performed. After that, the counter cutting operation is carried out. Finally, the panel is transferred to Buffer Area 1. Detailed process analysis of panel cutting station is illustrated in Table 5. 

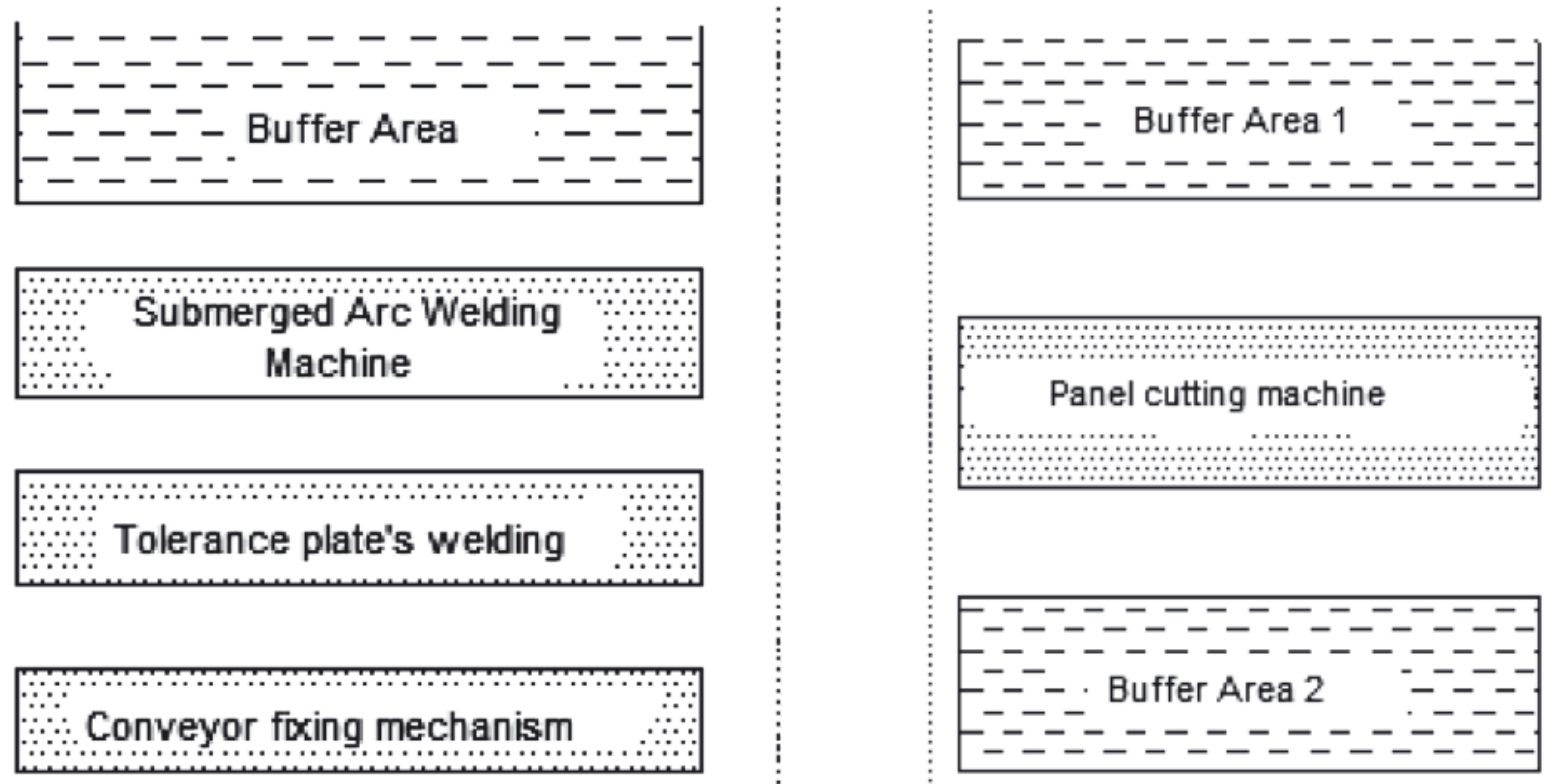

Fig. 3. General arrangement of panel production station (I3)

Fig. 4. General arrangement of panel cutting station (I4)

Tab. 5. The process analysis of panel cutting station (I4)

\begin{tabular}{|c|c|c|c|}
\hline $\begin{array}{l}\text { Activity } \\
\text { no. }\end{array}$ & Activity description & $\begin{array}{c}\text { Repetition } \\
\text { number of } \\
\text { activity } \\
\end{array}$ & $\begin{array}{c}\text { Activity } \\
\text { duration } \\
\text { (min.) }\end{array}$ \\
\hline 1 & The operator transports the panel to the panel cutting station & 2 & 1.334 \\
\hline 2 & The operator goes to bring the cutting program $\mathrm{CD}$ & 2 & 2 \\
\hline 3 & The operator takes the cutting program $\mathrm{CD}$ & 2 & 1 \\
\hline 4 & The operator goes back the cutting station with CD & 2 & 2 \\
\hline 5 & The operator loads the Program CD to the cutting machine & 2 & 2 \\
\hline 6 & The cutting machine moves on the counter line of the panel & 2 & 7.811 \\
\hline 7 & The cutting machine signs the reference points on the panel & 2 & 3.906 \\
\hline 8 & The cutting machine loads the reference points on itself. & 2 & 2 \\
\hline 9 & The operator runs the panel cutting machine & 2 & 0.5 \\
\hline 10 & Blasting and marking processes & 2 & 139.937 \\
\hline 11 & Cutting process & 2 & 101.457 \\
\hline 12 & The worker takes the marking pen & 2 & 2 \\
\hline 13 & Manuel marking process & 2 & 17.583 \\
\hline 14 & $\begin{array}{l}\text { Taking the outfitting parts and bringing them to the cutting } \\
\text { station. }\end{array}$ & 12 & 3 \\
\hline 15 & The workers put the outfitting parts on the panel. & 12 & 9 \\
\hline 16 & The worker runs the spot welding machine & 12 & 1.992 \\
\hline 17 & Spot welding process & 12 & 15.83 \\
\hline 18 & The worker runs the grinding machine & 12 & 1.992 \\
\hline 19 & Grinding process after the spot welding process & 6 & 7.334 \\
\hline 20 & The worker runs the TIG welding machine & 6 & 1.992 \\
\hline 21 & TIG welding process & 6 & 126.48 \\
\hline 22 & Grinding process after the TIG welding process & 6 & 7.49 \\
\hline 23 & $\begin{array}{l}\text { The conveyor transports the panel outside the panel cutting } \\
\text { station }\end{array}$ & 2 & 1.066 \\
\hline
\end{tabular}


In the same way, the detailed process analysis are performed for the other work stations. Because there are over 2500 work activities, it is impossible to present here. After the work activities and their durations are determined, the completion times of the work stations are calculated by considering the serial and parallel work activities. In Table 6, the completion times of the work stations are given. For instance, the process time of edge cutting station is 190 minutes. In other words, the edge cutting process of the plates, which constitute the panel of the double bottom block, takes 190 minutes.

Tab. 6. Station completion times of the current case

\begin{tabular}{|c|c|}
\hline Station name & Completion time (min.) \\
\hline Edge cutting & 190 \\
\hline Edge cleaning and sequencing & 203 \\
\hline Panel production & 622 \\
\hline Panel cutting & 356 \\
\hline Profile spot welding & 380 \\
\hline Profile TIG welding & 414 \\
\hline Section spot welding & 501 \\
\hline Section TIG welding & 660 \\
\hline Grinding & 99 \\
\hline Profile cutting & 410 \\
\hline Profile bending & 350 \\
\hline Nest cutting & 653 \\
\hline Pre-fabrication1 & 448 \\
\hline Pre-fabrication2 & 632 \\
\hline Jig & 1522 \\
\hline Plate bending (Press) & 1317 \\
\hline Block assembly & 2196 \\
\hline &
\end{tabular}

Simulation model of current production case (Step 4)

In this step, simulation model of the current production system is created. Fig. 5 depicts the simulation model of the current case and Tab. 7 shows the modules which are used in simulation model.

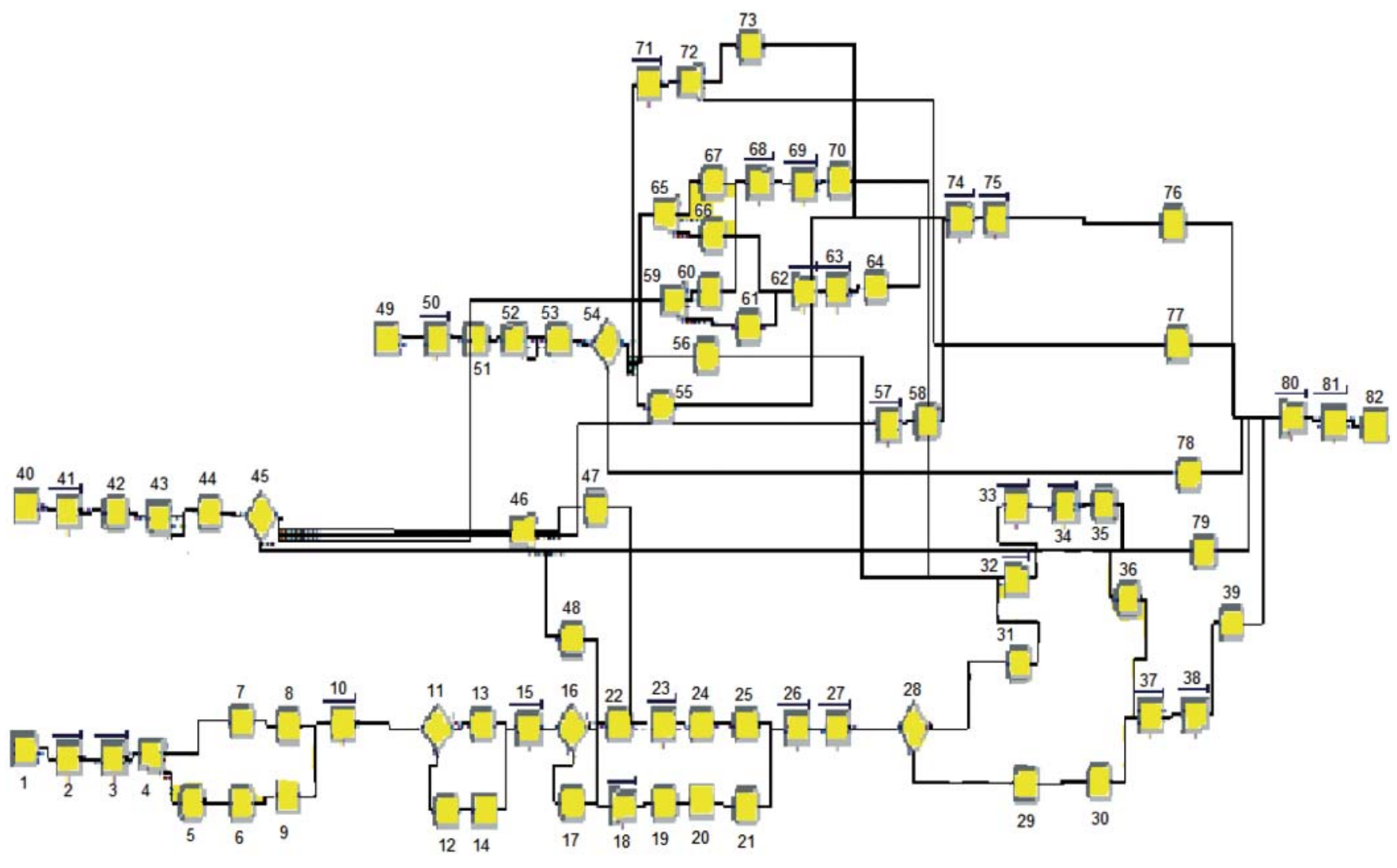

Fig. 5. Simulation model of the current case 
Tab. 7. Definition of module numbers

\begin{tabular}{|c|c|c|c|c|c|}
\hline $\begin{array}{c}\text { Module } \\
\text { no. }\end{array}$ & Module name & $\begin{array}{l}\text { Module } \\
\text { no. }\end{array}$ & Module name & $\begin{array}{c}\text { Module } \\
\text { no. }\end{array}$ & Module name \\
\hline 1 & Create1 & 29 & Assign13 & 57 & $\begin{array}{l}\text { Process of profile bending } \\
\text { (I11 station) }\end{array}$ \\
\hline 2 & $\begin{array}{c}\text { Process of plate edge cutting } \\
\text { (I1 station) }\end{array}$ & 30 & Assign 14 & 58 & Assign 27 \\
\hline 3 & Process of plate edge cleaning & 31 & Assign 15 & 59 & Seperate 5 \\
\hline 4 & Seperate1 & 32 & Batch3 & 60 & Assign 28 \\
\hline 5 & Assign 1 & 33 & $\begin{array}{l}\text { Process of section spot } \\
\text { welding(I7 station) }\end{array}$ & 61 & Assign 29 \\
\hline 6 & Assign2 & 34 & $\begin{array}{l}\text { Process of section TIG } \\
\text { welding (I8 station) }\end{array}$ & 62 & Batch 5 \\
\hline 7 & Assign3 & 35 & Assign16 & 63 & Process of pre-fabrication 1 \\
\hline 8 & Assign4 & 36 & Assign 17 & 64 & Assign 30 \\
\hline 9 & Delay1 & 37 & $\begin{array}{l}\text { Process of grinding } \\
\text { (I9 station) }\end{array}$ & 65 & Separate 6 \\
\hline 10 & $\begin{array}{l}\text { Process of panel production } \\
\text { (I3 station) }\end{array}$ & 38 & Batch4 & 66 & Assign 31 \\
\hline 11 & Decide1 & 39 & Assign 18 & 67 & Assign 32 \\
\hline 12 & Assign5 & 40 & Create2 & 68 & Batch 6 \\
\hline 13 & Assign6 & 41 & $\begin{array}{l}\text { Process of profile cutting } \\
\text { (I11 station) }\end{array}$ & 69 & Process of pre-fabrication 1 \\
\hline 14 & Delay2 & 42 & Assign19 & 70 & Assign 33 \\
\hline 15 & $\begin{array}{l}\text { Process of panel cutting } \\
\text { (I4 station) }\end{array}$ & 43 & Separate 2 & 71 & $\begin{array}{l}\text { Process of plate bending } \\
\text { (I15 station) }\end{array}$ \\
\hline 16 & Decide2 & 44 & Assign 20 & 72 & Separate 7 \\
\hline 17 & Assign 7 & 45 & Decide4 & 73 & Assign 34 \\
\hline 18 & Batch1 & 46 & Separate 3 & 74 & Batch 7 \\
\hline 19 & Assign 8 & 47 & Assign 21 & 75 & Process of jig (I14 station) \\
\hline 20 & Delay3 & 48 & Assign 22 & 76 & Assign 35 \\
\hline 21 & Assign9 & 49 & Create 3 & 77 & Assign 36 \\
\hline 22 & Assign 10 & 50 & $\begin{array}{l}\text { Process of nest cutting } \\
\text { (I12 station) }\end{array}$ & 78 & Assign 37 \\
\hline 23 & Batch2 & 51 & Assign 23 & 79 & Assign 38 \\
\hline 24 & Assign11 & 52 & Separate 4 & 80 & Batch 8 \\
\hline 25 & Assign 12 & 53 & Assign 24 & 81 & $\begin{array}{l}\text { Process of block assembling } \\
\text { (I16 station) }\end{array}$ \\
\hline 26 & $\begin{array}{l}\text { Process of profile spot } \\
\text { welding (I5 station) }\end{array}$ & 54 & Decide 5 & 82 & Dispose \\
\hline 27 & $\begin{array}{l}\text { Process of profile TIG } \\
\text { welding (I6 station) }\end{array}$ & 55 & Assign 25 & & \\
\hline 28 & Decide3 & 56 & Assign 26 & & \\
\hline
\end{tabular}

In ARENA simulation model, various modules are employed to create the simulation model of the production system. Tab. 8 represents the modules and their definitions. 
Tab. 8. Description of modules

\begin{tabular}{|c|c|}
\hline $\begin{array}{c}\text { Module } \\
\text { name }\end{array}$ & Description \\
\hline Create & $\begin{array}{c}\text { Describes the arrival time and quantity of the } \\
\text { materials entering into the production system }\end{array}$ \\
\hline Process & $\begin{array}{c}\text { Describes the work stations in the production } \\
\text { system }\end{array}$ \\
\hline Assign & $\begin{array}{c}\text { Makes assignments the products leaving any } \\
\text { work station and it is also used in assembly } \\
\text { operations }\end{array}$ \\
\hline Decide & $\begin{array}{c}\text { This module orients the products to the work } \\
\text { stations where they will go to }\end{array}$ \\
\hline Batch & $\begin{array}{c}\text { Used in assembly operations. It combines the } \\
\text { products for assembly operation }\end{array}$ \\
\hline Seperate & $\begin{array}{c}\text { Divides the main product into sub products. It is } \\
\text { usually used for cutting operations }\end{array}$ \\
\hline Dispose & Shows the exit of the production system \\
\hline
\end{tabular}

\section{Determination of throughput of current production case (Step 5)}

After the simulation model is created, the model is run along 720 hours. The current case has a capacity of producing 18 double bottom blocks at the end of the operation time of 720 hours. In other words, the current case can produce a double bottom block in 2400 minutes.

\section{Suggestions on the current case (Step 6)}

In the current production line, the assemblies of the outfitting and piping are carried out in the block assembly station. After the completion of the steel works, the outfitting assembly and then the piping assembly are carried out. Therefore, all these operations are done in serial way, which means more work load and longer lead times. If we can carry out the outfitting and piping operations in earlier work stations and distribute the work load, we can reduce the work load and the completion time of the block assembly station. By doing this, the waiting time in front of the block assembly area is lowered and the lead time of the double bottom block may be shorter. Tab. 9 depicts the suggestions on the current case.

Tab. 9. The suggestions on the current case

\begin{tabular}{|c|c|c|}
\hline $\begin{array}{l}\text { No. of } \\
\text { suggestions }\end{array}$ & Workstation & Description of suggestions \\
\hline 1 & Panel cutting & $\begin{array}{l}\text { The welding operations of the manholes on tanktop panel were carried out. These welding } \\
\text { operations are one side welding. In this way, the one side welding operations of the } \\
\text { manholes will be finished }\end{array}$ \\
\hline 2 & Panel cutting & The one side welding operations of the bottom plugs (two pieces) on hull panel \\
\hline 3 & Panel cutting & $\begin{array}{l}\text { The welding operations of the zincs (six pieces) } \\
\text { on hull panel were carried out and finished }\end{array}$ \\
\hline 4 & Pre-fabrication & The assemblies of vertical ladders (three pieces) were carried out on the sections \\
\hline 5 & Pre-fabrication & The assemblies of the zincs (thirty-two pieces) were carried out \\
\hline 6 & Pre-fabrication & Assemblies of pipe systems (twenty-six) on the module \\
\hline 7 & Pre-fabrication & $\begin{array}{l}\text { Manufacturing the module in pre-fabrication station (I13) } \\
\text { in order to assemble the piping systems }\end{array}$ \\
\hline 8 & Jig & Assembly of pipe systems (nine) on the curved panel assembly in jig station \\
\hline 9 & Block assembly & Assembly of one vertical ladder when the block is upside down \\
\hline 10 & Block assembly & Completing of the welding operations of two bottom plugs when the block is upside down \\
\hline 11 & Block assembly & Completing of the welding operations of four manholes when the block is in flat position \\
\hline 12 & Block assembly & Assembly of twenty doubling plates when the block is in flat position \\
\hline 13 & Block assembly & Assembly of two bilge wells when the block is in flat position \\
\hline 14 & Block assembly & Assembly of four zincs when the block is in flat position \\
\hline 15 & Block assembly & $\begin{array}{l}\text { Carrying out the outfitting and steel operations } \\
\text { in parallel way in the block assembly station }\end{array}$ \\
\hline 16 & Block assembly & $\begin{array}{l}\text { In the block assembly station (I16), in the steel operations, there are fourteen TIG welding } \\
\text { and spot welding workers in the current case. In the new case, the quantity of the TIG } \\
\text { welding and spot welding workers are sixteen for steel operations. The TIG welding and } \\
\text { spot welding operations are carried out by the same workers. And also, two spot welding } \\
\text { and TIG welding machines which are on idle are added to the station }\end{array}$ \\
\hline
\end{tabular}




\section{Application of the suggestions on the current case (Step 7)}

In this phase, the suggestions given in Step 6 are applied in the current simulation model in Fig. 5. Panel cutting, section spot welding, pre-fabrication, jig and block assembly stations were influenced by the suggestions on the current case and the completion times of these work stations are calculated again. Table 10 shows the completion times of each work stations in new case.

Tab. 10. Station completion times of the new case

\begin{tabular}{|c|c|}
\hline Station name & $\begin{array}{c}\text { Completion time } \\
\text { (min.) }\end{array}$ \\
\hline Edge cutting & 190 \\
\hline Edge cleaning and sequencing & 203 \\
\hline Panel production & 622 \\
\hline Panel cutting & 460 \\
\hline Profile spot welding & 380 \\
\hline Profile TIG welding & 414 \\
\hline Section spot welding & 284 \\
\hline Section TIG welding & 660 \\
\hline Grinding & 99 \\
\hline Profile cutting & 410 \\
\hline Profile bending & 350 \\
\hline Nest cutting & 653 \\
\hline Pre-fabrication1 & 621 \\
\hline Pre-fabrication2 & 632 \\
\hline Jig & 1634 \\
\hline Plate bending (Press) & 1317 \\
\hline Block assembly & 1073 \\
\hline
\end{tabular}

\section{Evaluation of the new case (Step 8)}

In the evaluation of the new case, Arena simulation program will be used. The new case manufactures 24 double bottom blocks at the end of 720 hours. That means the new case can produce a double bottom block in 1800 minutes.

\section{Comparison of the current and new cases (Step 9)}

Fig. 6 shows the quantity of the double bottom block manufactured in both cases at the end of 720 hours. While the current case produces 18 double bottom blocks, the new case produces 24 double bottom blocks.

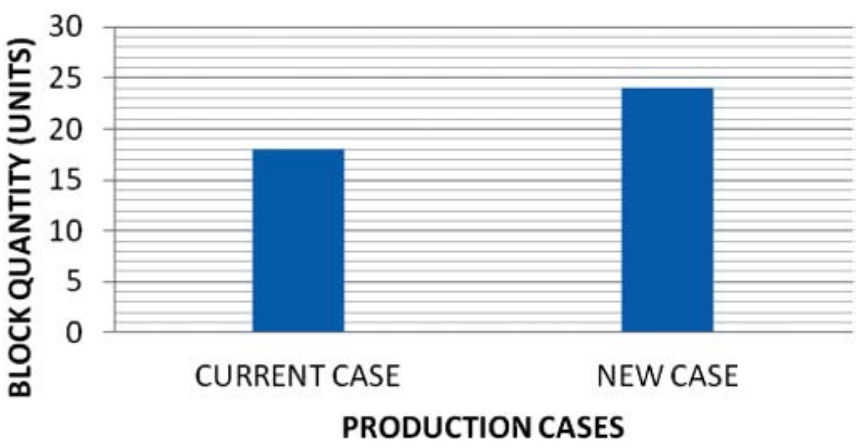

Fig. 6. Block quantity manufactured in the current and new cases
Fig. 7 shows the cycle times of the double bottom block for both cases. While a double bottom block is produced in 2400 minutes in the current case, in the new case, a double bottom block is produced in 1800 minutes.

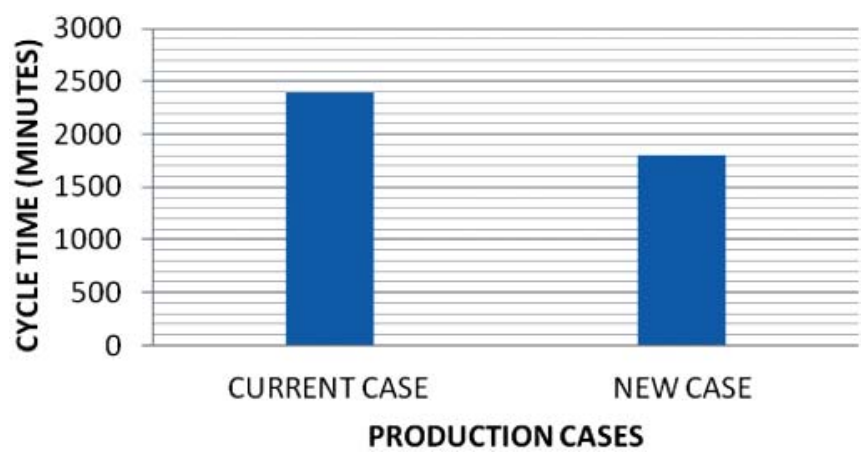

Fig. 7. Cycle times of the double bottom block for the current and new cases

It should be noted here that, no extra expenditures are paid during the transition from the current case to the new case. All the changes on the current case were performed by using the possibilities of the shipyards without purchasing any workers or equipments. Table 11 presents the need of additional equipment and manpower.

Tab. 11. Need of resources after changing

\begin{tabular}{|c|c|c|c|}
\hline $\begin{array}{c}\text { Suggestion } \\
\text { no. }\end{array}$ & Work Station & $\begin{array}{c}\text { Additional } \\
\text { equipment }\end{array}$ & $\begin{array}{c}\text { Additional } \\
\text { manpower }\end{array}$ \\
\hline 1 & Panel cutting & No need & No need \\
\hline 2 & Panel cutting & No need & No need \\
\hline 3 & Panel cutting & No need & No need \\
\hline 4 & Pre-fabrication & No need & No need \\
\hline 5 & Pre-fabrication & No need & No need \\
\hline 6 & Pre-fabrication & No need & No need \\
\hline 7 & Pre-fabrication & No need & No need \\
\hline 8 & Jig & No need & No need \\
\hline 9 & Block assembly & No need & No need \\
\hline 10 & Block assembly & No need & No need \\
\hline 11 & Block assembly & No need & No need \\
\hline 12 & Block assembly & No need & No need \\
\hline 13 & Block assembly & No need & No need \\
\hline 14 & Block assembly & No need & No need \\
\hline 15 & Block assembly & No need & No need \\
\hline 16 & Block assembly & No need & No need \\
\hline
\end{tabular}

\section{CONCLUSIONS}

In this study, some improvement suggestions with regard to outfitting and piping assembly operations were carried out on the shipyard production system. The improvements were applied on the block assembly station that was a bottleneck. The main changes on the current case were the pre-outfitting assembly operations and pre-piping assembly operations. According to simulation work, in the current case, the system can manufacture 18 blocks at the end of 720 hours. After the changes were applied on the current case, the new production case can produce 24 blocks at the end of 720 hours. So, the changes on the current case provide an improvement rate of $33 \%$ without additional expenditure. In other words, when the assembly operations of the outfitting and piping are carried 
out in earlier work stations, the throughput increases. The pre-outfitting and pre-piping assembly operations provide less cycle time. The authors strongly recommend the shipyards to perform outfitting and piping assembly operations in earlier stations instead of block assembly area since the cycle time of the block is considerably decreased.

\section{BIBILOGRAPHY}

1. Frankel E.G.: Impact of technological change on shipbuilding productivity, Journal of Ship Production, 1, 3, 174-183, 1985.

2. Inozu B., et al.: New horizons for shipbuilding process improvement, Journal of Ship Production, 22, 2, 87-98, 2006.

3. Eker E.: The application of the process improvement concept on the paint works, MSc Thesis, ITU Institute of Science, Istanbul, 1999.

4. Hardwick M., Kassel B., Crump B. and Garret S.: Improving shipyard manufacturing processes using STEP-NC, Journal of Ship Production, 21, 3, 170-176, 2005.

5. DiBarra C.: $5 S$-A tool for culture change in shipyards, Journal of Ship Production, 18, 3, 143-151, 2002.

6. Odabasi A.Y., Alkaner S., Olcer A. and Sukas N.: Reengineering of small and medium-sized ship production facilities: An example for Turkish Shipbuilding industry, Journal of Ship Production, 13, 1, 8-15, 1997.

7. Odabasi A.Y., et al.: Development and evaluation of Marmara Shipyard's expansion program, Contract Report, Istanbul, 1993.

8. Larson T., and Tice J.: Lean and EMS Integration Workshop, Environmental Technologies, Ship Production Panels, USA, 2005.

9. Lamb T.: Simulation-based performance improvement for shipbuilding processes, Journal of Ship Production, Vol. 22, No. 2, May, pp.49-65, 2006.

10.Shin J.G.: A modeling and simulation of production process in subassembly lines at a shipyard, Journal of Ship Production, Vol.20, No.2, May, pp.79-83, 2004.
11. Shin J.G.: A concept and framework for a shipyard layout design based on simulation, Journal of Ship Production, Vol.25, No.3, August, pp.126-135, 2009.

12.Alkaner S.: The Modelling and Analysis of Ship Production with Simulation: Case Study, PhD Thesis, ITU Institute of Science, Istanbul, 1998.

13.Greenwood A.G., Hill H.W.: Simulation Optimization Decision Support System for Ship Panel Shop Operations, Proceedings of the 2005 Winter Simulation Conference, pp. 2078-2086, 2005.

14.Kelton W.D., Sadowski R.P. and Sturrock D.T.: Simulation with Arena, Third edition, McGraw-Hill, 1998.

15.Fafandjel N., et al.: Procedure for measuring shipbuilding process optimization results after using modular outfitting concept, Urednistvo Casopisa Strojartvo, 50, 3, 141-150, 2008.

16. Yu H. and Ishida K.: The evaluation of the effectiveness of modular outfitting of engine room machines, Fourth International Conference on Marine Technology, 23-25 May, Poland, 391-399, 2001.

17.Baade R., et al.: Modular outfitting, Journal of Ship Production, 14, 3, 170-179, 1998.

Murat Ozkok, Assist. Prof.

Department of Naval Architecture and Marine Engineering, Karadeniz Technical University, 61530 Camburnu/Trabzon, TURKEY Phone: +90 462752 2805, Fax: +90 462752 2158, e-mail: muratozkok@ktu.edu.tr

I. Hakki Helvacioglu, Assoc. Prof.

Faculty of Naval Architecture and Ocean Engineering, Istanbul Technical University, 34469, Maslak/Istanbul, TURKEY Phone: +90 212285 6391, Fax: +90 2122856454 , e-mail: ismailh@itu.edu.tr 